\title{
SPECIAL ISSUE ACKNOWLEDGEMENTS
}

The authors and guest editors of this special edition of Rangelands would like to thank the Utah Agricultural Experiment Station, Dr. Paul Rasmussen, Director, for their joint sponsorship with the USDA-Agricultural Research Service, Poisonous Plant Research Laboratory (PPRL). We acknowledge the contributions of former research leader Lynn James to the Poisonous Plant Research Laboratory. We thank Lynnette Harris of the Utah Agricultural Experiment Station for editorial review of all manuscripts in addition to those individuals that provided scientific peer review. We also thank Holly Broome-Hyer of Utah State University, and Terrie Wierenga of the PPRL for assistance in graphic design of the covers and thank the entire staff of the Poisonous Plant Research Lab for suggestions, comments and helpful input.
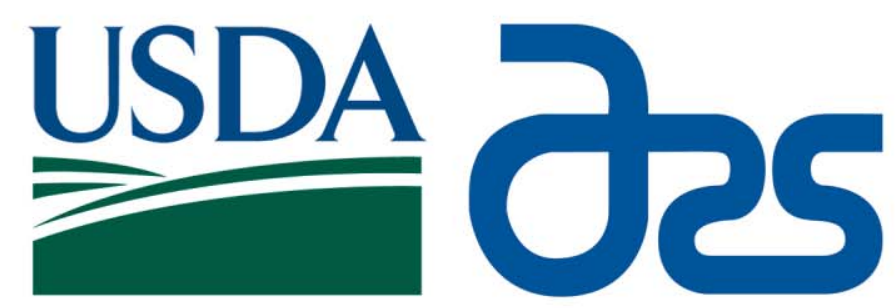

The Agricultural Research Service is the USDA's chief research agency. ARS conducts research to develop and transfer solutions to agricultural problems of high national priority.

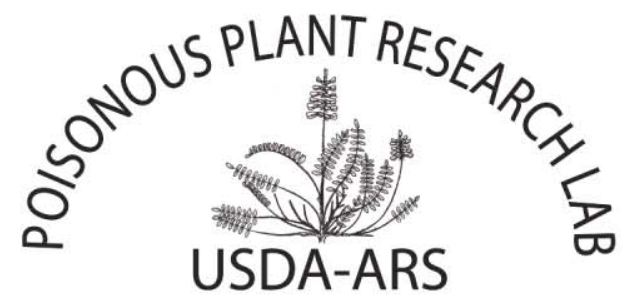

The goal of the Poisonous Plant Research Laboratory is to develop scientifically-based solutions and technologies for successful management of poisonous plant problems.

\section{Utah \\ Agricultural \\ Experiment Station}

The Utah Agricultural Experiment Station is part of the network of facilities and scientists advancing agricultural research at the nation's land-grant universities. 